\title{
Blood pressure and stroke in an elderly English population
}

\author{
J GRIMLEY EVANS \\ From the Academic Division of Geriatric Medicine, University of Oxford
}

SUMMARY The relation between blood pressure and subsequent stroke was examined in a four-year follow-up study of a geographically defined population sample of 2704 people aged 65 and over resident in South Tyneside in 1975. In men there was a significant relation between stroke and a history of diagnosed high blood pressure and the taking of antihypertensive medication. Stroke was not associated with either of these factors in women. Stroke incidence increased with blood pressure in men, more consistently with systolic than with diastolic pressure, but neither systolic nor diastolic pressure was related to stroke in women. In the population studied there seems little scope for the primary prevention of stroke in elderly women by detection and treatment of hypertension. Screening for the top quartile of blood pressure in men would have a sensitivity of $30 \%$ and a predictive value of $5 \%$ for stroke in the next four years. However, the extrapolation of epidemiological findings from one region or period to another may be expected to be less appropriate for the elderly than for younger people.

Although blood pressure and stroke are directly related in elderly members of North American populations, ${ }^{1}$ this has not been a universal finding. The Bergen study ${ }^{2}$ suggested that such a relation may disappear at higher ages. One report ${ }^{3}$ has suggested that there may be subpopulations of the elderly, with a relation between stroke and blood pressure apparent only in those who have established vascular disease or diabetes when first studied. We report here on the relation between blood pressure and stroke in a representative sample of an elderly population of Northern England.

\section{Methods}

The design of the Newcastle Age Research Group Stroke Study was outlined in a preliminary report. ${ }^{4}$ The findings to be presented here relate to a random five-sixths of a geographically defined population of 3036 people aged 65 and over $(1270$ men and 1766 women) living in a South Tyneside district in 1975. The overall response rate was $88 \%$ and the mean length of follow up was 44 months for men and 47 months for women. Research fieldworkers were specially recruited and trained health visitors or community nurses. Blood pressures were measured using the random-zero sphygmomanometer ${ }^{5.6}$ in the right arm with the subject seated and using phase 4 diastolic criteria. The routine cuff size was $12.5 \mathrm{~cm}$ by $22.5 \mathrm{~cm}$, but field workers carried a thigh cuff for use in the very obese. Blood pressure readings were taken at entry to the study, and revisits were offered at biennial intervals. At the first revisit a single blood pressure reading was taken and at the second there were two readings, one at the beginning of the interview and one at the end. Interviews and measurements were carried out in the respondents' own homes.

A number of follow-up procedures were instituted. For every person who had been interviewed or who had refused interview a reply paid envelope was inserted in the general practitioner record folder and flagged with a distinctive red tag. General practitioners were asked to return these cards to the survey office if the patient died, moved from the area or had a possible stroke. The possible stroke patients notified in this way were visited by medical members of the survey team. On the anniversary of each respondent's entry to the study, general practitioner record cards were inspected by medical or nursing staff from the survey team to identify possible cerebrovascular results not already reported. The death notices of local newspapers were inspected daily, and copies of death certificates relating to residents in the study were made available to the research team at regular intervals by the community physicians. At two-year intervals respondents were revisited for an abbreviated interview and examination, special attention being paid to possible symptoms of 
cerebrovascular disease occurring since original enrolment. Print-outs were obtained annually from the Regional Health Authority, giving data on hospital admissions of patients aged 65 and over with addresses in the study area who had been admitted to hospital with a diagnosis of stroke. With the permission of relevant clinicians, hospital notes were then retrieved and inspected. Decisions on the diagnosis of stroke were made by the Medical Director of the study, without knowledge of the findings of the initial interview and examination. The clinical criteria for stroke required the acute or subacute onset of focal neurological disorder involving the cerebrum or brainstem lasting more than, or leading to death within, 24 hours and of presumed vascular origin. Subjects with globally impaired consciousness in the absence of demonstrable focal neurological signs were accepted as suffering from cerebrovascular episodes if toxic or metabolic causes had been reasonably excluded. Follow-up observations were completed in 1982.

Incidence rates in the study were completed using total person-months of observation from entry to death, withdrawal or first stroke episode. Variances and confidence limits on standardised incidence ratios (SIR) comparing groups with and without risk factors of interest were calculated on the basis of five-year age groups and using the formulae of Flanders. ${ }^{7}$

\section{Results}

One hundred and forty-four stroke events were observed in the study sample over the follow-up period. In five cases $(8 \%)$ among men and 20 cases (24\%) among women, diagnosis was based on death certification but supplemented in most by coroners' reports or verbal enquiries from general practitioners. Diagnosis for 25 men $(41 \%)$ and 24 women ( $29 \%)$ was based on examination by medical members of the survey team. In the remainder, diagnosis was based on inspection of the hospital notes or interview with a witness. Table 1 shows calculated stroke incidence rates per 12000 person-months by sex and age group. Comparison of stroke incidence rates in participants and non-participants showed no significant difference, SIRs among non-participants being 0.92 in both sexes.

Table 1 Stroke incidence rates per 12000 person-months

\begin{tabular}{llllllll}
\hline & \multicolumn{1}{c}{ Men } & & & \multicolumn{2}{l}{ Women } \\
\cline { 2 - 5 } \cline { 5 - 7 } Age $(y r)$ & No. & Rate & $S E$ & & No. & Rate & $S E$ \\
\hline $65-74$ & 37 & 13 & 2 & & 43 & 11 & 2 \\
$75-$ & 24 & 25 & 5 & & 40 & 21 & 2 \\
\hline
\end{tabular}

Five per cent of men and 3\% of women had a general practitioner record of previous cerebrovascular disease at the time of entry to the study. SIRs of subsequent further strokes among these subjects were 6.3 in men $(p<0.01)$ and 2.6 in women $(p<0.01)$. These subjects have been excluded from further analysis.

BLOOD PRESSURE MEASUREMENTS AT ENTRY Table 2 shows mean and standard deviations by sex and age group of the blood pressure readings taken at entry to the study. In men mean systolic pressures are highest in the 70-74 year age group; in women the peak occurs in the 75-79 age group, and in both sexes there is a decline thereafter. In both sexes mean diastolic pressures diminish with age.

The general practitioner records of 1442 of the respondents contained a previous blood pressure reading. Correlation coefficients between these readings and the survey pressures were calculated within each sex and five-year age group, tested for homogeneity, and pooled. The pooled coefficients were 0.37 for systolic and 0.31 for diastolic pressures, both highly significant $(\mathrm{p}<0.001)$.

In order to facilitate correction for age-associated differences, blood pressures were categorised into quartile scores based on the distribution of pressure within each sex and five-year age group. Table 3 sets out the quartile cutting points used for this purpose.

\section{BLOOD PRESSURE MEASUREMENTS DURING} FOL LOW - UP

Of the respondents who had their blood pressures measured, $73 \%$ had more than one reading. An indication of the reliability of the blood pressure measurements provided by the study is given by the correlation between these multiple readings. For those subjects who had had four readings, pooled

Table 2 Entry blood pressure readings by sex and age group; means and standard deviations (SD)

\begin{tabular}{|c|c|c|c|c|c|c|}
\hline \multirow[b]{2}{*}{$\operatorname{Age}(y r)$} & \multicolumn{3}{|c|}{ Men } & \multicolumn{3}{|c|}{ Women } \\
\hline & No. & Mean & $S D$ & No. & Mean & $S D$ \\
\hline \multicolumn{7}{|l|}{ Systolic: } \\
\hline $65-69$ & 367 & 156.2 & $26 \cdot 5$ & 412 & 161.8 & 26.5 \\
\hline $70-74$ & 248 & 159.0 & $23 \cdot 1$ & 372 & $164 \cdot 7$ & $25 \cdot 2$ \\
\hline $75-79$ & 141 & 157.1 & $26 \cdot 2$ & 249 & $168 \cdot 1$ & $26 \cdot 2$ \\
\hline $80-84$ & 79 & 158.0 & $30 \cdot 0$ & 133 & $167 \cdot 2$ & 26.9 \\
\hline $85-$ & 30 & 158.4 & $25 \cdot 3$ & 62 & $159 \cdot 2$ & $28 \cdot 3$ \\
\hline \multicolumn{7}{|l|}{ Diastolic: } \\
\hline $65-69$ & 367 & 87.4 & $16 \cdot 0$ & 412 & 91.8 & 16.5 \\
\hline $70-74$ & 248 & 86.4 & 14.7 & 372 & 90.9 & $16 \cdot 5$ \\
\hline $75-79$ & 141 & $84 \cdot 8$ & 16.2 & 249 & 90.6 & 15.8 \\
\hline $80-84$ & 79 & $84 \cdot 3$ & 19.4 & 133 & $90 \cdot 4$ & $16 \cdot 2$ \\
\hline $85-$ & 30 & 82.4 & $14 \cdot 2$ & 62 & 87.4 & $17 \cdot 8$ \\
\hline
\end{tabular}


Table 3 Quartile points for entry blood pressure readings

\begin{tabular}{|c|c|c|c|c|c|c|}
\hline \multirow[b]{2}{*}{ Age(yr) } & \multicolumn{3}{|l|}{ Men } & \multicolumn{3}{|c|}{ Women } \\
\hline & $25 \%$ & $50 \%$ & $75 \%$ & $25 \%$ & $50 \%$ & $75 \%$ \\
\hline \multicolumn{7}{|l|}{ Systolic: } \\
\hline $65-69$ & 136.5 & 154.5 & 174.5 & 142.5 & 159.5 & 178.5 \\
\hline $70-74$ & $141 \cdot 5$ & 158.5 & 174.5 & $147 \cdot 5$ & 162.5 & $180 \cdot 5$ \\
\hline $75-79$ & 136.5 & 153.5 & 176.5 & $150 \cdot 5$ & 168.5 & 184.5 \\
\hline $80-84$ & 137.5 & 156.5 & $170 \cdot 5$ & 147.5 & 164.5 & 185.5 \\
\hline 85 & 136.5 & 152.5 & $170 \cdot 5$ & 142.5 & 155.5 & 172.5 \\
\hline \multicolumn{7}{|l|}{ Diastolic: } \\
\hline $65-69$ & $77 \cdot 5$ & $87 \cdot 5$ & $97 \cdot 5$ & $81 \cdot 5$ & $90 \cdot 5$ & $100 \cdot 5$ \\
\hline $70-74$ & 76.5 & $85 \cdot 5$ & 94.5 & 79.5 & 90.5 & $101 \cdot 5$ \\
\hline $75-79$ & $74 \cdot 5$ & $84 \cdot 5$ & 96.5 & $78 \cdot 5$ & 89.5 & $101 \cdot 5$ \\
\hline $80-84$ & $72 \cdot 5$ & 82.5 & 91.5 & 78.5 & 90.5 & $100 \cdot 5$ \\
\hline $85-$ & $72 \cdot 5$ & 82.5 & 89.5 & $76 \cdot 5$ & $85 \cdot 5$ & 97.5 \\
\hline
\end{tabular}

correlation coefficients were calculated as described above. Coefficients between first and second blood pressure readings (taken on separate occasions and not always by the same observer) averaged 0.51 for systolic and 0.42 for diastolic pressures. Coefficients between the third and fourth blood pressure readings (taken at different times on the same visit) averaged 0.86 for systolic and 0.83 for diastolic. All these coefficients were highly significant $(p<0.001)$.

\section{HISTORY OF HIGH BLOOD PRESSURE}

The data were examined for evidence that a past history of hypertension, treated or not, was a risk marker for stroke. Ninety per cent of respondents ( $91 \%$ of men and $89 \%$ of women) recalled having had their blood pressure measured previously. Of those who recalled a previous blood pressure measurement, $16 \%$ of men and $27 \%$ of women had been told that their pressure was high. Table 4 shows the relation between a history of raised blood pressure and the incidence of first strokes observed in the respondents. This analysis is restricted to respondents who reported previous blood pressure measurements in order to obviate bias arising from subjects with established vascular disease being most likely to have had their blood pressures measured. In men there is a significant relation between history of raised blood pressure and stroke incidence, but this is not apparent in women.

\section{ANTIHYPERTENSIVE MEDICATION}

Treatment with some forms of medication may be useful as an index of a previous diagnosis of hypertension. As shown in table 5, the incidence of stroke was more than three times higher in men taking specific hypertensive medication other than diuretics and beta-blockers (mostly methyldopa but including clonidine, debrisoquine, and guanethidine) than among men not taking these drugs. Using the Kolmogorov-Smirnov two-sample test, ${ }^{8}$ the quartile blood pressure scores (both systolic and diastolic of both men and women) taking hypotensive medication were found to be significantly higher $(p<0.01)$ than those of subjects not taking such medication.

Table 5 also shows an increased stroke incidence ratio among men taking diuretics, some of which may have been prescribed for hypertension, and a smaller but significant increase in incidence was also seen in women taking diuretics. However, there was no significant difference in blood pressure quartile scores between those respondents taking diuretics and those not.

\section{BLOOD PRESSURE AND RISK OF STROKE}

Table 6 presents the analysis relating stroke incidence rates to systolic blood pressure quartiles. In neither sex is there a consistent trend; incidence rates for men in the upper two quartiles are 16 per 12000 personmonths (SE 3.3) compared with 12 (SE 2.8) in the lower two quartiles $(95 \%$ confidence interval on the SIR was 80 to 268). In women, rates in the upper two quartiles were 13 per 12000 person-months (SE 2.3) and in the lower two quartiles 15 (SE 2.5) the $95 \%$ confidence interval on the SIR being 50 to 140 . The relation of stroke to systolic pressure in men seems to be J-shaped with the lowest incidence in the second quartile and the highest in the fourth. There is no evidence in table 6 that the separate age groups differ in the relation between stroke and systolic pressure.

Table 4 Number of first strokes, crude incidence rates (per 12000 person-months) among respondents with (+) and without (-) a history of raised blood pressure. Respondents reporting previous blood pressure measurement only

\begin{tabular}{|c|c|c|c|c|c|c|c|c|c|c|}
\hline \multirow[b]{3}{*}{$\operatorname{Age}(y r)$} & \multicolumn{5}{|l|}{ Men } & \multicolumn{5}{|c|}{ Women } \\
\hline & \multicolumn{2}{|l|}{+} & \multicolumn{3}{|l|}{-} & \multicolumn{2}{|l|}{+} & \multicolumn{3}{|l|}{-} \\
\hline & No. & Rate & No. & Rate & $S I R$ & No. & Rate & No. & Rate & $S I R$ \\
\hline $\begin{array}{l}65-74 \\
75-\end{array}$ & $\begin{array}{l}7 \\
6\end{array}$ & $\begin{array}{l}21 \\
69\end{array}$ & $\begin{array}{l}17 \\
13\end{array}$ & $\begin{array}{l}10 \\
22\end{array}$ & & $\begin{array}{r}10 \\
9\end{array}$ & $\begin{array}{l}13 \\
27\end{array}$ & $\begin{array}{l}21 \\
21\end{array}$ & $\begin{array}{l}10 \\
20\end{array}$ & \\
\hline All & 13 & 31 & 30 & 13 & $247^{* *}$ & 19 & 17 & 42 & 14 & 124 \\
\hline
\end{tabular}


Table 5 Proportions of respondents taking prescribed medications and standardised incidence ratios (SIR) of stroke

\begin{tabular}{lcllll}
\hline & \multicolumn{2}{l}{ Men } & & \multicolumn{2}{l}{ Women } \\
\cline { 2 - 3 } \cline { 6 - 7 } \cline { 5 - 6 } Medication & \% taking & SIR & & \% taking & SIR \\
\hline Digitalis & 9 & $335^{* *}$ & & 10 & $231^{* *}$ \\
Diuretics & 18 & $293^{* *}$ & & 27 & $153^{* *}$ \\
Hypotensives & 7 & $336^{* *}$ & & 11 & 128 \\
\hline
\end{tabular}

$* * \mathrm{p}<0.01$

Table 7 presents a similar analysis of the relation between stroke and diastolic blood pressure as recorded at entry to the study. Again, there are no consistent gradients, but for men incidence rates are significantly $(p<0.01)$ higher in the two upper quartiles of blood pressure (19 per 12000 personmonths, SE 3.5) than in the two lower quartiles (10 per 12000 person-months, SE 2.5 ). The $95 \%$ confidence interval on the SIR was 115 to 412 . There is no evidence of a relation between stroke incidence and diastolic blood pressure in women, rates in both upper two quartiles and in the lower two quartiles of pressure being 14 (SE 2.5) with $95 \%$ confidence interval on the SIR being 60 to 161 .

In table 8 the analysis is repeated for quartiles of average blood pressures in those respondents who had more than one blood pressure reading made during the study. Exclusion of a proportion of the respondents produced imbalance between the quartile groups and so SIRs have been calculated. A suggestive but not entirely consistent gradient of SIR with increasing systolic pressure is seen in men, but there is no relation seen in women. There is no consistent gradient of SIR with diastolic pressure level in either sex.

The possibility had to be considered that the relation between stroke incidence and blood pressure had been obscured by the inclusion of 'noise' in the form of misdiagnosed stroke events. The least definite group of ascertained stroke events were those identified from death certificates only. The analysis of stroke incidence against entry blood pressure quartile was repeated using only stroke events ascertained by means other than death certification alone. The results were similar to that seen when all stroke events were included in the analysis. In particular, no relation of

Table 6 Number of first strokes and incidence rates (per 12000 person-months) by quartile of entry systolic pressure

\begin{tabular}{|c|c|c|c|c|c|c|c|c|}
\hline \multirow[b]{3}{*}{$\operatorname{Age}(y r)$} & \multicolumn{8}{|c|}{ Quartile } \\
\hline & \multicolumn{2}{|l|}{$I$} & \multicolumn{2}{|l|}{2} & \multicolumn{2}{|l|}{3} & \multicolumn{2}{|l|}{4} \\
\hline & No. & Rate & No. & Rate & No. & Rate & No. & Rate \\
\hline \multicolumn{9}{|l|}{ Men: } \\
\hline $65-74$ & 7 & 13 & 3 & 5 & 5 & 9 & 9 & 17 \\
\hline $75-$ & 3 & 16 & 6 & 29 & 6 & 33 & 4 & 19 \\
\hline All & 10 & 14 & 9 & 11 & 11 & 15 & 13 & 17 \\
\hline \multicolumn{9}{|l|}{ Women: } \\
\hline $65-74$ & 11 & 14 & 9 & 12 & 5 & 6 & 7 & 9 \\
\hline $75-$ & 5 & 13 & 10 & 24 & 10 & 26 & 8 & 21 \\
\hline All & 16 & 14 & 19 & 16 & 15 & 13 & 15 & 13 \\
\hline
\end{tabular}

Table 7 Number of first strokes and incidence rates (per 12000 person-months) by quartile of entry diastolic pressure

\begin{tabular}{|c|c|c|c|c|c|c|c|c|}
\hline \multirow[b]{3}{*}{$\operatorname{Age}(y r)$} & \multicolumn{8}{|c|}{ Quartile } \\
\hline & \multicolumn{2}{|l|}{1} & \multicolumn{2}{|l|}{2} & \multicolumn{2}{|l|}{3} & \multicolumn{2}{|l|}{4} \\
\hline & No. & Rate & No. & Rate & No. & Rate & No. & Rutc \\
\hline \multicolumn{9}{|l|}{ Men: } \\
\hline $\begin{array}{l}05-14 \\
75-\end{array}$ & 3 & $\begin{array}{r}9 \\
15\end{array}$ & $\begin{array}{l}2 \\
5\end{array}$ & $\begin{array}{r}4 \\
23\end{array}$ & 4 & $\begin{array}{l}20 \\
21\end{array}$ & $\begin{array}{l}6 \\
7\end{array}$ & $\begin{array}{l}10 \\
39\end{array}$ \\
\hline All & 8 & 10 & 7 & 9 & 15 & 20 & 13 & 17 \\
\hline \multicolumn{9}{|l|}{ Women: } \\
\hline $65-74$ & 7 & 9 & 11 & 14 & 8 & 10 & 6 & 7 \\
\hline 75 & 8 & 22 & 6 & 16 & 10 & 23 & 9 & 24 \\
\hline All & 15 & 14 & 17 & 14 & 18 & 15 & 15 & 13 \\
\hline
\end{tabular}


blood pressure to risk of subsequent stroke emerged among the women, the group most affected by exclusion of strokes ascertained by death certification only.

The analysis of tables 6 and 7 was repeated omitting respondents who were taking major hypotensive agents or diuretics or beta-blockers (whether for treatment of hypertension or not). No significant gradient with entry systolic pressure was apparent in men, the incidence rate in the lower two quartiles being 9 (SE 2.7) compared with 13 (SE 3.2) in the two upper quartiles. The $95 \%$ confidence interval of the SIR was 73 to 340 . In women the rates were 10 (SE 2.4) and 13 (SE 2.8 ) respectively; the $95 \%$ confidence interval on the SIR was 68 to 242 . For diastolic pressure at entry to the study, incidence rates in men were 8 (SE 2.5) in the lower two quartiles and 14 (SE 3.4) in the upper. The $95 \%$ confidence interval on the SIR was 72 to 335 . In women the corresponding rates were 11 (SE 2.5) and 12 (SE 2.7), with $95 \%$ confidence interval of the SIR 60 to 212 . The exclusion of respondents taking medication affecting blood pressure did not, therefore, materially affect the relation between blood pressure and stroke incidence.

Table 9 compares the trends of stroke incidence rates with quartile of entry blood pressure in respondents with diagnosed diabetes mellitus or evidence of established vascular disease at entry to the study. Respondents were allocated to the vascular disease group if they had Minnesota code ${ }^{9}$ items 1.1 , $1.2,1.3,4.1,4.2,5.1,5.2,7.1$ or 8.3 on their limb-lead electrocardiograms, ${ }^{10}$ if there was a general practitioner record of previous cerebrovascular events, or if there was a positive questionnaire response indicative of intermittent claudication or a general practitioner record of peripheral vascular disease. There is no evidence that the two groups differ in the relation between stroke and blood pressure.

\section{Discussion}

Although North American studies have indicated blood pressure as a major risk factor for stroke in the elderly, doubts have been expressed as to whether this

Table 8 Number of first strokes, incidence rates (per 12000 person-months) and standardised incidence ratios (SIR) by quartile of average pressure. Respondents with more than one blood pressure recording only

\begin{tabular}{|c|c|c|c|c|c|c|c|c|}
\hline & \multicolumn{8}{|c|}{ Quartile } \\
\hline & \multicolumn{2}{|l|}{1} & \multicolumn{2}{|l|}{2} & \multicolumn{2}{|l|}{3} & \multicolumn{2}{|l|}{4} \\
\hline & No. & SIR & No. & $S I R$ & No. & $S I R$ & No. & SIR \\
\hline \multicolumn{9}{|l|}{ Men: } \\
\hline Systolic & 4 & 54 & 5 & 65 & 11 & 143 & 10 & 138 \\
\hline Diastolic & 7 & 90 & 7 & 85 & 9 & 122 & 7 & 105 \\
\hline \multicolumn{9}{|l|}{ Women: } \\
\hline Systolic & 8 & 83 & 11 & 110 & 13 & 114 & 8 & 90 \\
\hline Diastolic & 10 & 98 & 13 & 122 & 10 & 94 & 7 & 82 \\
\hline
\end{tabular}

Table 9 Numbers of stroke events with standardised incidence ratios (SIR) by quartiles of entry blood pressure and diagnostic group

Group A comprises respondents with diabetes mellitus or evidence of vascular disease at entry to the study (see text for criteria); group B comprises all other respondents

\begin{tabular}{|c|c|c|c|c|c|c|c|c|}
\hline & \multicolumn{8}{|c|}{ Quartile } \\
\hline & \multicolumn{2}{|l|}{1} & \multicolumn{2}{|l|}{2} & \multicolumn{2}{|l|}{3} & \multicolumn{2}{|l|}{4} \\
\hline & No. & SIR & No. & SIR & No. & $S I R$ & No. & SIR \\
\hline $\begin{array}{ll}\text { Group A: } & \\
\text { Men: } & \text { Systolic } \\
& \text { Diastolic }\end{array}$ & $\begin{array}{l}5 \\
5\end{array}$ & $\begin{array}{l}89 \\
76\end{array}$ & $\begin{array}{r}10 \\
5\end{array}$ & $\begin{array}{r}149 \\
78\end{array}$ & $\begin{array}{l}8 \\
8\end{array}$ & $\begin{array}{r}95 \\
101\end{array}$ & $\begin{array}{r}6 \\
11\end{array}$ & $\begin{array}{r}72 \\
133\end{array}$ \\
\hline $\begin{array}{l}\text { Women: Systolic } \\
\text { Diastolic }\end{array}$ & $\begin{array}{l}8 \\
9\end{array}$ & $\begin{array}{l}125 \\
156\end{array}$ & $\begin{array}{l}7 \\
5\end{array}$ & $\begin{array}{r}121 \\
86\end{array}$ & $\begin{array}{l}5 \\
6\end{array}$ & $\begin{array}{r}83 \\
138\end{array}$ & $\begin{array}{l}6 \\
6\end{array}$ & $\begin{array}{l}76 \\
90\end{array}$ \\
\hline $\begin{array}{ll}\text { Group B: } & \\
\text { Men: } & \text { Systolic } \\
& \text { Diastolic }\end{array}$ & $\begin{array}{l}7 \\
5\end{array}$ & $\begin{array}{r}106 \\
74\end{array}$ & $\begin{array}{l}4 \\
3\end{array}$ & $\begin{array}{l}57 \\
45\end{array}$ & $\begin{array}{r}6 \\
11\end{array}$ & $\begin{array}{r}99 \\
179\end{array}$ & $\begin{array}{l}9 \\
7\end{array}$ & $\begin{array}{l}145 \\
109\end{array}$ \\
\hline $\begin{array}{l}\text { Women: Systolic } \\
\text { Diastolic }\end{array}$ & $\begin{array}{r}11 \\
9\end{array}$ & $\begin{array}{l}97 \\
84\end{array}$ & $\begin{array}{l}14 \\
12\end{array}$ & $\begin{array}{r}121 \\
95\end{array}$ & $\begin{array}{r}9 \\
13\end{array}$ & $\begin{array}{r}84 \\
101\end{array}$ & $\begin{array}{l}10 \\
10\end{array}$ & $\begin{array}{l}96 \\
90\end{array}$ \\
\hline
\end{tabular}


is necessarily true in Britain, ${ }^{11}$ and the British literature is notable for its emphasis on the undesirable side effects of antihypertensive treatment, ${ }^{12}$ especially in the elderly..$^{13}$ Nonetheless, the recent reports of the European Working Party on Hypertension in the Elderly ${ }^{1415}$ will encourage the treatment of high blood pressure in older people, and the possible relevance of blood pressure surveys in the elderly population to primary prevention of stroke needs to be explored. There has not been a sizeable prospective study of stroke incidence in a British population; a Scottish study was of a very small number of subjects, ${ }^{16}$ and the South Wales study, which identified blood pressure as being associated with a number of vascular diseases including stroke in respondents aged over 65 , was restricted to mortality ${ }^{17}$ which could be misleading.

We believe that our study sample was representative of a northern English community. It was geographically defined, with a high response rate, and the incidence of stroke in the respondents did not differ from that in the non-respondents. Standardised mortality ratios (all causes of death) in the study sample were 114 in men and 104 in women compared with England and Wales, as would be expected for a northern industrial population. The distribution of causes of death in the sample was very close to national figures, cerebrovascular disease accounting for $15 \%$ compared with national figures of $14 \%$ (adjusted for age and sex). Our observed incidence rates for stroke are similar to those observed in other western populations ${ }^{18}$ and are also similar in their rise with age and sex ratio.

The blood pressure readings in this study also seem similar to those of other surveys of the elderly. Owing to differences in technique, it is not appropriate to make detailed comparisons of levels of pressures observed in our study with reports from elsewhere. The age trends in our data are strikingly similar to those reported from South Wales. ${ }^{17}$ Mean systolic pressures in men rise to a peak in the 70 to 74 year age group and then decline. In women the peak occurs at ages 75 to 79 . In both sexes, mean diastolic pressures decline throughout the age range studied. These declines in mean pressure with age might partly reflect differential mortality, but there is probably also a true fall in blood pressure with age in some elderly individuals. The curvilinear relation of mean blood pressure levels to age was also seen for median pressures (table 3).

In men, there was a clear relation of stroke incidence to an interview history of diagnosed raised blood pressure although this was not seen in women. There was also a strong relation of stroke incidence to the taking of major hypotensive drugs, but again only in men. The blood pressures of respondents, of both sexes, who were taking major hypotensive medication were higher than average.

No clear and consistent pattern of association of blood pressure level with subsequent stroke incidence emerged from analysis of blood pressure readings taken at entry to the study. For systolic pressure it is possible to postulate a $\mathrm{J}$-shaped trend in men (table 6 ) but this is not seen in women nor for diastolic pressure in either sex. Total mortality rates show a $\mathrm{J}$-shaped relation to blood pressure in the elderly, ${ }^{17}$ which, it has recently been suggested, may be due to a deleterious effect of low blood pressure on survival in subjects with coronary heart disease. ${ }^{19} \mathrm{~A} \mathrm{~J}$-shaped relation of stroke to blood pressure has not been identified although there is a suggestion of such a relation in the findings of the Bergen study. ${ }^{2}$ Overall incidence rates were higher among men with above median diastolic pressures than among those with below median pressures, but again this was not so among women. Analysis of quartile scores based on the average of readings for those subjects who had had more than one (table 8 ) produced a more striking gradient of stroke incidence with systolic pressure in men but still failed to demonstrate any clear relation to diastolic pressures or in women. It was disappointing that as high a proportion of incident cases were not examined by survey staff as has been achieved in some other studies. ${ }^{20}$ However, exclusion of those stroke cases that were based on death certification alone did not alter the pattern of stroke incidence against entry blood pressures. The exclusion of respondents taking medication that might have modified their blood pressures diminished rather than accentuated the pattern in men and failed to produce a significant gradient in women.

In the Chicago stroke study, ${ }^{3}$ a relation between blood pressure and stroke was found only in those elderly subjects who had evidence of vascular disease, including cerebrovascular disease or diabetes or uraemia at entry. We attempted to replicate this observation by dividing respondents into groups according to the presence or not of diabetes and established vascular disease. This analysis (table 9) did not uncover a monotonic positive relation between stroke and blood pressure in the group with vascular disease.

The failure to find a positive relation between blood pressure and stroke in women led us to various attempts to validate our blood pressure readings and to assess their reproducibility. The correlation coefficients between separate readings during the follow-up period provide a measure of reassurance, particularly as the random-zero sphygmomanometer was used which prevents successive readings being influenced by previous readings. The significant correlations with previous blood pressure readings recorded in general practitioner records provide 
additional validation. It seems resonable to assume that any absence of a relation between blood pressure and stroke in our study is unlikely to be due to inadequate technique in blood pressure measurement. Indeed, given the care taken over training of the fieldworkers, our readings are likely to compare favourably in reliability and validity. with those taken during the course of ordinary nursing or medical practice.

In summary, the relation between stroke and blood pressure levels in this study appears to differ between the sexes. There is no evidence of any relation at all in women, with regard to either previous high blood pressure or blood pressure levels measured in the study. In men, past high blood pressure is associated with a significantly increased risk of stroke. There is also an association in men between stroke and current blood pressure, and this relation is most apparent when more than one blood pressure reading is used in allocating respondents to blood pressure strata (table 8 ). The relation is more clear for systolic than for diastolic pressure, which may reflect greater accuracy of readings or that systolic pressure reflects both hypertension and, through its relation to arterial compliance, vascular damage.

We conclude that, as a means of primary prevention of stroke in the population studied, screening elderly women for high blood pressure would not be of benefit. Screening elderly men might be of use provided that multiple readings of pressure were used. Table 8 suggests, however, that screening the top $25 \%$ of the average systolic blood pressure distribution in men would have a sensitivity of only $30 \%$ with a predictive value of $5 \%$ for stroke over four years of follow-up.

Given the consistent relation between stroke incidence and blood pressure in both sexes at younger adult ages, our failure to find any evidence that blood pressure levels, past or present, are related to stroke in elderly women is at first sight puzzling. There are, however, several reasons why risk factors may be differently and, in particular, less clearly associated with disease in old age than earlier in life. ${ }^{21}$ Factors leading to variation with age, sex, and locality in the relation of blood pressure to stroke may lie in the immediate environment of elderly people but are perhaps more likely to be found in their past histories, in the pattern of interacting risk factors, and in the selective survival that may have affected their birth cohort. On theoretical grounds we may suspect that the risk factor pattern for stroke in the elderly northern English will change over the next decades to one more similar to that of younger and American populations. For the time being our findings warn against the unthinking translation of findings from other areas or other age groups to particular elderly communities.

Thanks are due to the general practitioners of Whickham, who cooperated so fully in this study, and to the staff of the Newcastle Age Research Group Medical Gerontology Program for their scrupulous work on the survey. The work was supported by grants from the Department of Health and Social Security and from the British Foundation for Age Research.

\section{References}

${ }^{1}$ Kannel WB. Blood pressure and the development of cardiovascular disease in the aged. In: Caird FI, Dall JLC, Kennedy RD, eds. Cardiology in old age London: Plenum, 1976; 143-75.

${ }^{2}$ Holme I, Waaler HT. Five-year mortality in the City of Bergen, Norway according to age, sex and blood pressure. Acta Med Scand 1976; 200: 229-39.

${ }^{3}$ Ostfeld AM, Shekelle RB, Klawans H, Tufo HM. Epidemiology of stroke in an elderly welfare population. Am J Publ Hlth 1974; 64: 450-8.

${ }^{4}$ Evans JG, Prudham D, Wandless I. Risk factors for stroke in the elderly. In: Barbagallo-Sangiorgi G, Exton-Smith $\mathrm{AN}$, eds. The ageing brain: neurological and mental disturbances. New York: Plenum, 1980; 113-26.

${ }^{5}$ Wright BM, Dore CF. A random-zero sphygmomanometer. Lancet 1970; i: 337-8.

${ }^{6}$ Evans JG, Prior IAM. Experience with the random-zero sphygmomanometer. Br J Prev Soc Med 1970; 24: 10-5.

${ }^{7}$ Flanders WD. Approximate variance formulas for standardised rate ratios. J Chron Dis 1984; 37: 449-54.

${ }^{8}$ Siegel S. Nonparametric statistics for the behavioral sciences. New York: McGraw-Hill, 1956.

${ }^{9}$ Rose GA, Blackburn H. Cardiovascular survey methods Geneva: World Health Organisation, 1968.

${ }^{10}$ Evans JG, Tunbridge WMG. Information loss in limblead electrocardiograms compared with twelve-lead tracings in a population survey among the elderly. Age and Ageing 1976; 5: 56-61.

${ }^{11}$ Fry J. Natural history of hypertension. A case for selective non-treatment. Lancet 1974; ii: 431-3.

12 Anonymous. Trials and tribulations of a symptom-free hypertensive physician receiving the best of care. Lancet 1977; ii: 291-2.

13 Jackson G, Pierscianowski TA, Mahon W, Condon J. Inappropriate antihypertensive therapy in the elderly. Lancet 1976; ii: 1317-8.

${ }^{14}$ Amery A, Birkenhager W, Brixko R, et al. Efficacy of antihypertensive drug treatment according to age, sex, blood pressure, and previous cardiovascular disease in patients over the age of 60. Lancet 1986; ii: 589-92.

15 Amery A, Birkenhager W, Brixko R, et al. Mortality and morbidity results from the European Working Party on high blood pressure in the elderly trial. Lancet 1985; i: 1349-54.

${ }^{16}$ Milne JS. A longitudinal study of blood pressure and stroke in older people. J Clin Exp Gerontol 1981; 3: 135-59.

${ }^{17}$ Miall WE, Brennan PJ. Hypertension in the elderly: the South Wales Study. In: Onesti G, Kimm KE, eds. Hypertension in the young and old. New York: Grune and Stratton, 1981; 277-83. 
${ }^{18}$ Report of the Joint Committee for Stroke Facilities. 1: Epidemiology for stroke facilities planning. Stroke 1972; 3: 359-71.

${ }^{19}$ Cruickshank JM, Thorp JM, Zacharias FJ. Benefits and potential harm of lowering high blood pressure. Lancet 1987; i: 581-4.
${ }^{20}$ Oxfordshire Community Stroke Project. Incidence of stroke in Oxfordshire: first year's experience of a community stroke register. $\mathrm{Br}$ Med J 1983; 287: 713-7.

${ }^{21}$ Evans JG. Prevention of age-associated loss of autonomy: epidemiological approaches. J Chron Dis 1984; 37: 353-63.

\section{The First United Kingdom Healthy Cities Conference.}

\section{8-30 March 1988, Liverpool}

The Healthy Cities Project is an initiative by the World Health Organization European Office to give support to the renaissance of public health which is evident in many urban areas. Eleven cities throughout Europe have been working with WHO, and networks of other cities which have experience of developing new health promotion initiatives are appearing in many countries.

The UK Healthy Cities Conference is intended to encourage this process in the UK. Various aspects of city life which can influence health will be considered, including Architecture, Environmental Design, Urban Regeneration, Housing Policy, Employment, Medical Care, Education, Transport, and Recreation.

Further details may be obtained from: Ms Julie Kirkham, UK Healthy Cities Conference, Environmental Health Department, 6 Brougham Terrace, West Derby Road, Liverpool L6 $1 \mathrm{JH}$. 